\title{
A Contrastive Analysis of Two English Versions of the Diplomatese in Zuozhuan from the Perspective of Pragmatic Equivalence
}

\author{
Yongmei He \\ Foreign Languages Department \\ Xiamen University Tan Kah Kee College \\ Zhangzhou, China
}

\begin{abstract}
Based on an all-sided investigation of the diplomatic language materials in Zuozhuan, we have made a contrastive analysis between two English versions of Diplomatiese of Zuozhuan from the perspective of retrieving and re-expressing the illocutionary force(one is The Chun Ts'ew with the Tso Chuen translated by James Legge, the other is Zuozhuan translated by Hu Zhihui). On the basis of the practical application we find that speech act theory can be a practical guide to translation and try to summarize some revelatory points on the speech acts theoretic approach to achieve pragmatic equivalence in translation.
\end{abstract}

Keywords-pragmatic equivalence; illocutionary force; diplomatic language; Zuozhuan; speech act theory

\section{INTRODUCTION}

Illocutionary force, which is one of the main research objects in speech act theory, is a distinctive feature of Zuozhuan, a famous historical and literary work of the Spring and Autumn period in China. According to the theory of speech acts, human beings do not simply produce sentences that are true or false, but rather perform speech actions through utterances. Many good examples of the application of speech acts theory can be found in the diplomatic language of Zuozhuan in which plentiful implicit actions and forces are contained and expressed. From the angle of illocutionary force transmission, we are going to tentatively make a contrastive analysis between the two English versions of the Diplomatese of Zuozhuan (one is The Chun Ts'ew with the Tso Chuen translated by James Legge, the other is Zuozhuan translated by $\mathrm{Hu}$ Zhihui). From the analysis we try to check if speech act theory can be a practical guide to achieve pragmatic equivalence in translation.

\section{A CONTRASTIVE ANALYSIS OF TwO ENGLISH}

VERSIONS OF THE DIPLOMATESE IN ZUOZHUAN FROM THE PERSPECTIVE OF PRAGMATIC EQUIVALENCE

\section{A. Context}

The author of Zuozhuan is good at choosing proper writing skills to express illocutionary force according to various contextual factors. Based on this recognition, here we analyze the translation of the diplomatic language from the aspect of the transmission of illocutionary force in all kinds of contexts. To give a complete yet clear definition of context may prove to be difficult. Here we adopt Bell's understanding of it as (1991:20): "the totality of the shared or mutual knowledge possessed by the participants in the communicative act." Following this definition, we attempt to divide the contexts in Zuozhuan into the following categories which may be of some help to the practice of translation.

1) Lexical-grammatical context: This type of context is the set of internalized rules of a particular language by which all the speakers of this language community abide by. Concerning the rendering in this category, the translator has to pay attention to the unique lexical and grammatical rules and principles of different language systems. For example:

（1）小人戚, 谓之不免。君子怒, 以为必归。（僖公- -十五 年)

James Legge's version:

The inferior people are full of distress, saying he will not get off; but superior men, judging by their own estimate of things, think he is sure to return.

\section{Hu Zhihui’s version:}

The ordinary people grieve for him but say he will never escape harm. The gentlemen put themselves in Qin's place and surmise that he will be allowed to return.

“小人” and “君子” are two words frequently appeared in Chinese classics to refer to two types of persons. Generally speaking, these two types of persons are divided by noble character. Those who have noble character and moral integrity are addressed “君子” respectfully by others, while those base or mean persons who have no noble character are usually addressed “小人”. But “小人” has a relatively broader sense; it can also refer to those persons of low positions in society. In the example above, the two nouns were used by Xia Sheng, the chief minister of Jin, to describe two attitudes the Jin people held toward their ruler's future, for at that time Duke Hui of Jin had been captured by Duke Mu of Qin. Xia Sheng purposely described the two opinions of the Jin people to Duke $\mathrm{Mu}$ in order to imply that if he was a real man of noble character he should set Duke Hui free. So here “小人” 
and “君子” are carrying their general meanings and the distinction between them is mainly virtue and moral but not social status or personal ability. Yet James Legge translates the two words as "the inferior people" and "the superior men", which lays stress on disparity in social estate and consequently causes unfaithfulness to the original meanings. From this perspective, Hu Zhihui's version of "the ordinary people" and "the gentlemen" is more appropriate.

2) Discourse context: Other than the lexicalgrammatical context, the exact meaning of a unit must be analyzed in the wider context of the surrounding discourse. Within the category of discourse context, the translator must be able to make co-textual and intertextual inferences from the surrounding text environment for the adequate rendering of the text to be translated.

Consider the following examples:

（2）无禄, 献公即世。穆公不忘旧德, 俾我惠公用能奉祀于晋; 又不能成大勋, 而为韩之师。(成公・十三年)

\section{James Legge's version:}

When, through our evil fate, Duke Heen left the world, duke Muh was not unmindful of their old friendship, and assisted our duke Hwuy, so that he presided over the sacrifices of Tsin. But he could not complete his great service to Tsin, and there ensued the battle of Han.

\section{Hu Zhihui's version:}

But when further misfortune fell and Duke Xian of Jin, our former ruler, passed away, Duke Mu of Qin, your former sovereign, recalling the old ties of gratitude, made it possible for Duke Hui to become the new ruler of Jin and to carry on the sacrifices at our national altar. However, unable to achieve any appreciable merit, Duke $\mathrm{Mu}$ of Qin caused the Battle of Han.

This example is also taken from the speech made by Wei Xiang. At first Wei Xiang admitted that Duke Mu of Qin had done something for Jin, namely assisting Duke Hui to become the new ruler of the state of Jin. But he then pointed out that, instead of offering more help to Jin, Duke $\mathrm{Mu}$ caused the battle of Han between Jin and Qin. From the context we can infer that “又不能成大勋” is a condemnation based on the acknowledgement of Duke Mu's former merits. So in Hu's version, the translation of this sentence as "unable to achieve any appreciable merit" is apparently incorrect. Comparatively speaking, James Legge's version of "But he could not complete his great service to Tsin" is better. But the translation would be more faithful if he had changed the sentence into a structure expressing comparative degree.

3) Communicative context: To appreciate the full illocutionary meaning of the original text, the translator has to put it in an actual communicative situation and consider all the possible circumstances involved in the original communication. Only after he has sufficiently grasped the communicative significance of the work can he adequately reconstruct the context in the TL.

Consider the following examples:
（3）齐侯使宾媚人赂以纪虔、玉馨与地, 不可, “则听客之所 为”。(成公・二年)

\section{James Legge's version:}

The marquis sent Pin Me-jin [Kwoh Tso; but why he is thus designated here has not been fully explained] to offer [the invaders] the steamer and the musical stone of jade from $\mathrm{Ke}$, and the territory [of Wei and Loo, which I had taken]; and if this would not satisfy them, to ascertain what they wanted.

\section{Hu Zhihui's version:}

On hearing of this, the ruler of Qi dispatched Bin Meiren to offer as gifts the ceremonial vessel and the jade musical instrument from the State of $\mathrm{Ji}$, together with a certain amount of Qi territories. If these gifts were not acceptable, the Duke resolved, he would take up arms and resist.

The example above is about a battle between the state of Jin and Qi in the second year of Duke Cheng of Lu. Before sending troops to resist the attack of Jin, the ruler of Qi dispatched Bin Meiren to sue for peace. The Duke of Qi had two kinds of preparations, one was to seek peace with Jin if Jin accepted Qi's offerings, and the other was to draw the sword if the enemy refused to take peaceful negotiations. So after assigning Bin Meiren to offer some gifts to Jin, he added the sentence “不可, 则听客之所为”. If we put the sentence into the original communicative context, we can find that the illocutionary act in his words is not a compromise but a resolution to take the second step, that is, to make war. So the direct translation in James Legge's version is not appropriate for it bears the implication of willing to accept any requirements of the state of Jin and fails to convey the author's real intention. And Hu's version is comparatively better in achieving pragmatic equivalence. But it seems to go too far in carrying out the free translation.

4) Cultural context: The last but not least factor in determining the meaning of a text is the cultural context. After all, words only have meanings in terms of the total cultural setting. So in his practice, the translator has to look from time to time into the wider cultural environment for important clues for the correct understanding of the SL and the re-expressing of it in the TL. According to He (何自然 1992), this consideration of social and cultural situation is included in the study of sociopragmatics. For example:

（4）天祚明德, 有所底止。成王定鼎于搂叞, 卜世三十, 卜年七 百，天所命也。周德虽衰，天命未改。鼎之轻重，未可问 也。（宣公・三年）

James Legge's version:

Heaven blesses intelligent virtue; on that its favor rests. King Cheng fixed the tripods in JiaRu, and divined that the dynasty should extend through 30 reigns, over 700 years. Though the virtue of Zhou is decayed, the decree of Heaven is not yet changed. The weight of tripods may not yet be inquired about.

\section{Hu Zhihui's version:}

The bright virtue bestowed by Heaven has its limit and end. When Emperor Cheng of Zhou fixed the jiuding bronze 
vessel in the place named Jiaru he divined by the tortoiseshell to determine its future duration. The outcome was ' 700 years in 30 generations'. This was mandated by Heaven. Thus, though the virtue of the Zhou dynasty may have begun to decline, the mandate of Heaven is by no means changed. Therefore, it is unwise to inquire whether the jiuding bronze vessel is heavy or light.

As we have discussed, “鼎” is a special kind of tripod caldron in ancient China which symbolizes the royal power. If one owns “鼎”, he will certainly own the whole country. In the period of Eastern Zhou the empire of Zhou was declining and the royal position was turning down. Some vassal states showed no respects to the Emperor of Zhou, especially Duke Zhuang of Chu. He reviewed his troops in the domain of Zhou court, aiming to demonstrate his military force. He even dared to ask boldly about the “鼎” of Zhou in the palace. Wang Sunman, a minister of Zhou who saw through the wild ambition of Duke Zhuang, showed no impression of weakness to Duke Zhuang and answered his inquiry calmly and wittily. The above example is just taken from the diplomatic speech made by Wang Sunman. At first, he drew support from Heaven to express that Zhou dynasty was doomed to extend through 700 years and 30 generations. Although Zhou was declining now, it was still blessed by Heaven. In the last sentence he ended his speech with a suggestion “鼎之轻重, 未可问也”, which actually performed the illocutionary act of warning. By making use of the decree of Heaven, Wang Sunman noticed sternly to Duke Zhuang that it was not time for him to inquire about the royal power and he should get rid of that wild ambition.

\section{B. Sentence Pattern}

1) Rhetorical question: Rhetorical questions often express the opposite meanings to what they appear to have. The author of Zuozhuan has given much attention to the use of rhetorical questions in order to carry illocutionary force in diplomatic language. In translating rhetorical questions, the translator should understand the author's intention correctly and find a proper way to transform it from the SL into the TL. Sometimes the same structure of rhetorical question can be used in translation to convey the same illocutionary force, but sometimes the translator should not rigidly adhere to the original form. For example:

（5）自今无有代其君任患者, 有一于此, 将为翏乎? （成公・二 年)

\section{James Legge's version:}

Henceforth no one will take upon himself in his room the danger to which his ruler is exposed. One such person there is here; and will you put him to death?

\section{Hu Zhihui’s version:}

If you execute me, no one will again be willing to endure hardship in his lordship's place!

In a battle between Qi and Jin, Feng Choufu, a minister of Qi, imitated the ruler of Qi and helped the ruler to escape from the danger of being caught. When Han Jue, a general of Jin, captured Feng Choufu and presented him to his superior
$\mathrm{Xi} \mathrm{Ke}, \mathrm{Xi} \mathrm{Ke}$ decided to put the prisoner to death. At that moment, Han Jue, moved by Feng's ligeance and courage, said the sentence above to beg for leniency for Feng. The rhetorical question used here is intended to perform the illocutionary act of a directive. As the function can be done with the same structure both in Chinese and English, the literal translation in James Legge's version can properly convey the illocutionary force. Comparatively speaking, Hu's version has done too many changes to the original and has gone too far.

2) Conditional sentence: If there is a certain logic relationship contained in a conditional sentence, this kind of sentence is usually called suppositive judgment. In this type of sentence, the speaker hides his intention of his utterances purposely and will not tell the listeners what to do directly. He leaves the choice to the listeners and leads them to find the answer following his hint outside the sentence itself. Because of the existence of cultural barrier, sometimes the translator has to emphasize the hint or make the clue clear in order to achieve the pragmatic equivalence in the translation of this type of sentence. For example:

（6）寡人不倿，能合其众而不能离也。若君不还，无所逃命。 (僖公・十五年)

James Legge's version:

Feeble as I am, I have assembled my multitudes, and cannot leave you. If you will not return to your own state, I will certainly not evade your commands.

\section{Hu Zhihui's version:}

I am a man of no ability, capable of calling my force together but not of dispersing them. If you refuse to withdraw from my territory, I will have no choice but to accept your challenge to battle.

In logic, one proposition is a necessary condition of another when the second cannot be true while the first is false. The speaker of the sentence above was Han Jian who wanted to request that hostilities began in a battle between the state of Qin and Jin. Here Han Jian suggested that if there was no such condition “君不还”, there would be no such result as “无所逃命”. If taken literally, “无所逃命” means “I have no way to evade your commands", but this translation is not clear enough to explain the implicit meaning of the sentence and may make the reader feel confused. So here the translator has to express clearly what on earth the consequence is if one chooses the condition of “君不还”. From the context, we know that the real intention of Han Jian in this utterance is that if you do not return, we will have to fight. In the translation of $\mathrm{Hu}$ Zhihui's version, the translator has successfully transmitted the illocutionary force in the conditional sentence, while James Legge's version applies a too literal way and fails to achieve the pragmatic equivalent effect.

\section{Figure of Speech}

1) Simile and metaphor: Simile and metaphor are two kinds of figure of speech that are most frequently used. 
Simile is that figure of speech in which two essentially unlike things are compared, often in a phrase introduced by like or as. Metaphor is another kind of comparison in which a word or phrase that ordinarily designates one thing is used to designate another, thus making an implicit comparison. They both help to make the narration or argumentation more vivid and easy to understand. In translation of these rhetorical devices, it is important to grasp the author's real intention hidden in the comparison and equally transmit the meaning between lines from the SL to TL. Consider the following examples:

（7）康公, 我之自出, 又欲阙翦我公室, 倾覆我社稷, 帅我螯 贼, 以来荡摇我边疆, 我是以有令狐之役。（成公・十三 年)

\section{James Legge's version:}

[Your] duke K'ang was the son of a daughter of Tsin, but he still wished to uproot and cut down our House, and to overturn our altars. He gave an army to a vile insect [The Kung-tsze Yung of Tisn] to disturb our borders, in consequence of which we had the engagement at Ling-hoo [See VI.xii.5].

\section{Hu Zhihui’s version:}

Being a nephew of our late sovereign (Duke Xiang), though, Duke Kang sought all the more to destroy our ducal house and overthrow our government, leading a band of noxious pests (i.e. Gongzi Yong and his followers) to contend for the throne, so as to bring turmoil to our borders. As a consequence, we were forced to engage in the battle of Linghu.

In this sentence, Wei Xiang of Jin accused Duke Kang of Qin for supporting the betrayer of Jin, Gongzi Yong, and helping him to disturb Jin's borders. At that time, Gongzi Yong was a prince of Jin and lived in Qin as a guest. Here he used a metaphor to compare Gongzi Yong to a vile pest, indicating that Gongzi Kong was a major enemy to the state of Jin. But in Hu Zhihui's English version the comparison is made between a group of persons including Gongzi Yong and a band of noxious pests, which is unfaithful to the original. Judging from the representation of the original message, we can see James Legge has provided a correct and clear translation to the comparison.

2) Euphemism: Euphemism is the act of substituting a mild, indirect, or vague term for one considered harsh, blunt, or offensive. In order to be polite and friendly, the ancient Chinese people are fond of applying euphemisms in their speeches. In diplomatic speeches, euphemism is a good way to carry some illocutionary forces. In euphemism the speaker purposely hides his real intention in communication and reveals only some information as a clue to make the listeners dig out the contained implicit meanings. With regard to the translation of euphemism, on one hand the translator should transmit the full illocutionary force contained in this figure of speech, on the other hand he should also try to preserve the effect that euphemism is supposed to achieve. For example:
（8）臣辱戎士，敢告不敏，摄官承乏。（成公・二年）

James Legge's version:

And being now in the position of a soldier, I venture to tell you of my want of ability, and to undertake the office [of your charioteer], so supplying your present need.

\section{Hu Zhihui's version:}

Now that I find myself in the company of your honored warriors, I make bold to offer my unworthy services, and, though it is far from my will, to take Your Highness prisoner!

In a battle between Qi and Jin, the army of Qi was defeated. The sentence above is taken from the words said by Han Jue, a general of Jin, when he was going to take the ruler of Qi prisoner. According to the military protocol and ancient courtesy of the Spring and Autumn period, if a minister of one country has captured the ruler of another country, he should still admit to be a subject of the ruler and show respect to him. So in the sentence above Han Jue expressed his intention of taking the duke prisoner in a very euphemistic and tactful way. If taken literally, “摄官承乏” means "to take the job of a vacant position", but this translation will make the output far from the author's intention and fail to tell the readers what is going to happen. And this is just the reason why James Legge's literal version fails to achieve pragmatic equivalence in the rendering of this sentence. Here the actual meaning of the utterance should be "to take the job of taking you prisoner". In order to make the implication clear enough, the translator has to give up the euphemism used here and expresses the true intention directly, just as what $\mathrm{Hu}$ has done in his version.

\section{CONCLUSION}

On the basis of the practical application we try to summarize some revelatory points on the speech acts theoretic approach to translation as follows:

\section{A. Comprehension}

Comprehension is the first step in translating process and also the basic one. Through the practical analysis of the translation of DZ, we find some channels that illocutionary force may be transmitted and that should bring to the translator's attention:

- In order to get a thorough and all-sided understanding of the original text, the translator has to pay much attention to the contexts. When a translator is translating a complete text, the full meaning of the source text has to be inferred from the original context. In translation, this consideration depends on the translator's beliefs as well as his/her social and cross-cultural knowledge.

- The intended meaning or illocutionary force of a message may be hidden in discourse deixis. It is necessary to reveal the force of the deixis in translation so as to achieve the pragmatic equivalence. A negation of one such word may cause the incomplete understanding of the author's implicit intention. 
- Full comprehension of a sentence also includes the comprehension of the illocutionary force embedded in the sentence pattern. The translator should not assume an equation between linguistic forms and communicative functions in translation. Sometimes the translator could use the same structure as the SL used to convey the same illocutionary force, but sometimes it should not rigidly adhere to the original form.

\section{B. Expression}

Based on the translator's correct, thorough and all-sided comprehension of the source text, expression in translation means to transmit naturally and appropriately the full content of the source text with the TL to the TL reader. In order to translate the illocutionary force successfully, we may propose four points that the translator must pay attention to:

- According to Peter Newmark (1981), literal translation is always the best provided it has the same communicative and semantic effect. So the first choice for the translator is to decide whether the work can be done in a literal way, at the same time ensuring that the intended or illocutionary meaning is transferred and the same response is created. The extent to which a work can be adequately translated by a literal method is primarily determined by the linguistic, social and cultural distance between the two languages.

- Languages do not differ basically in what they can talk about but in the manner that they speak of objects or experiences. As a result, in many cases, the same illocutionary force of one language can be completely re-expressed in another language by taking another form. This substitution can be done to both words and sentences. In order to achieve pragmatic equivalence, a proper language form is required to express the same illocutionary force carried by the original form. The translator should not be misled into thinking that commands are uniquely associated with imperative sentences, and questions with interrogative sentences.

- In cases when certain expressions cannot be translated literally in the target language; when the implicit meanings intended by the author can only be appreciated within a certain social, cultural and historical background, the translator usually has two choices to solve the problem: one is to give up the specific description of the SL and retaining only the pragmatic equivalent effect of the message; the other is to add his or her explanations to the translation work, thus facilitating the target reader's understanding of the work.

- In circumstances when the expression particular to a culture is an essential part of the overall force of the whole text, it is a must to retain this exotic flavor in the translated text. And when the explanation made directly in the target text either makes the text clumsy or sound unnatural, the translator has to use the method of making footnotes, for instance, the translation of some quotations in Zuozhuan.

\section{REFERENCES}

[1] $\mathrm{Hu}$ Zhihui,(translated into English), Chen Kejiong,(translated into Modern Chinese). 1996, Zuo's Commentary. Hunan: Hunan People's Publishing House.

[2] Liao, Qiyi. 2001. Contemporary English translation theory.Wuhan: Hubei Education Press.

[3] Suo Zhenyu. 2000. Courses on Pragmatics. Beijing: Peking University Press.Legge, J. (trans.) 1960. The Chun Ts'ew with the Tso Chuen, Hongkong: Hongkong University Press

[4] Zhiji Liu, 1978, Shitong • Xushi, Shiht 'ung explanation, Shanghai: Guji Press, 174.

[5] Austin, J. L. 1962. How to Do Things with Words. Oxford: Clarendon Press.

[6] Leech, G. 1983. Principles of Pragmatics. London: Longman Group UK Ltd.

[7] Searle, J. 1969. Speech Act: An Essay in the Philosophy of Language. Cambridge: Cambridge University Press.

[8] Searle, J. 1975. Indirect speech acts. In Cole P. \& Morgan J. (Eds.), Syntax and semantics. Vol. 3: Speech acts, 59-82. New York: Academic Press.

[9] Yule, G. 2000. Pragmatics. Shanghai: Shanghai Foreign Language Education Press. 